\title{
Films from Glyoxal-Crosslinked Spruce Galactoglucomannans Plasticized with Sorbitol
}

\author{
Kirsi S. Mikkonen, ${ }^{1}$ Mari I. Heikkilä, ${ }^{1}$ Stefan M. Willför, ${ }^{2}$ and Maija Tenkanenn ${ }^{1}$ \\ ${ }^{1}$ Department of Food and Environmental Sciences, University of Helsinki, P.O. Box 27, 00014 Helsinki, Finland \\ ${ }^{2}$ Process Chemistry Centre, Åbo Akademi University, Porthansgatan 3, 20500 Åbo, Finland
}

Correspondence should be addressed to Kirsi S. Mikkonen, kirsi.s.mikkonen@helsinki.fi

Received 23 June 2011; Revised 22 September 2011; Accepted 3 October 2011

Academic Editor: Annamaria Celli

Copyright ( $\odot 2012$ Kirsi S. Mikkonen et al. This is an open access article distributed under the Creative Commons Attribution License, which permits unrestricted use, distribution, and reproduction in any medium, provided the original work is properly cited.

Films were prepared from a renewable and biodegradable forest biorefinery product, spruce O-acetyl-galactoglucomannans (GGMs), crosslinked with glyoxal. For the first time, cohesive and self-standing films were obtained from GGM without the addition of polyol plasticizer. In addition, glyoxal-crosslinked films were prepared using sorbitol at 10, 20, 30, and 40\% (wt.-\% of GGM). Glyoxal clearly strengthened the GGM matrix, as detected by tensile testing and dynamic mechanical analysis. The elongation at break of films slightly increased, and Young's modulus decreased with increasing sorbitol content. Interestingly, the tensile strength of films was constant with the increased plasticizer content. The effect of sorbitol on water sorption and water vapor permeability (WVP) depended on relative humidity (RH). At low RH, the addition of sorbitol significantly decreased the WVP of films. The glyoxal-crosslinked GGM films containing $20 \%$ sorbitol exhibited the lowest oxygen permeability (OP) and WVP of the studied films and showed satisfactory mechanical performance.

\section{Introduction}

Replacing oil-based plastics with renewable and biodegradable materials is one of the most important aims of current packaging research. Present biodegradable polymers include starch, cellulose, polylactide (a synthetic polyester produced from lactic acid), and polyhydroxyalkanoates (polyesters produced by microorganisms from carbohydrates or lipids) [1]. However, the biodegradation of polylactide was recently found not to meet the OECD standard [2]. Thus, plant biopolymers such as polysaccharides and proteins have at least two advantages over synthesized biodegradable plastics: they can be used without the polymerization step, and their biodegradability and environmental compatibility are assured.

Hemicelluloses are the most abundant plant polysaccharides apart from cellulose. They are biosynthesized in large quantities in the majority of trees and terrestrial plants. In spite of their abundance, the industrial utilization of hemicelluloses is minor in comparison with the use of starch and cellulose. The most abundant hemicelluloses in softwoods are mannans. Obtaining $\mathrm{O}$-acetyl galactoglucomannans
(GGMs) from spruce wood holds potential as a forestry industry byproduct, but they are currently partially removed with the waste water of thermomechanical pulping. The latter is considered a disadvantage, as it reduces pulp and paper yields and increases the impact load on either the environment or waste water management [3]. GGM can be recovered at reasonable cost from the process water by purification, ultrafiltration, and alcohol precipitation or spraydrying [3, 4]. GGMs can also be obtained from wastewater of fiberboard mills by ultrafiltration [5] or from wood chips by pressurized hot-water extraction [6]. GGM consist of backbones of $\beta$-1,4-D-mannopyranosyl $(\operatorname{Man} p)$ and $\beta$ 1,4-D-glucopyranosyl (Glcp) units carrying single $\alpha$-Dgalactopyranosyl $(\mathrm{Gal} p)$ residues that are $(1 \rightarrow 6)$-linked to Man $p$ residues, and acetyl substituents attached to C2 or C3 positions of Manp [7]. An average molar ratio of Man $p$ : Glcp: Galp in water-soluble spruce GGM is $4: 1: 0.5$ and the degree of acetylation is 15\% [8].

GGM can be used as such or mixed with other polysaccharides to form a raw material for biodegradable films with promising oxygen barrier properties [9-11]. When used 
alone, however, GGMs require rather large amounts of external plasticizer (30-40 wt.-\% of GGM), such as glycerol or sorbitol, to form cohesive self-standing films. Due to the rather low molar mass of GGM $(20-60 \mathrm{kDa})$, the tensile strength of the films is relatively low. As part of our recent studies, we attempted to improve the mechanical performance of GGM films by using cellulose nanowhiskers [12] and microfibrillated spruce pulp cellulose [13] as reinforcement. The use of $15 \%$ microfibrillated cellulose enabled film formation from GGM and measurement of tensile properties using a small sample size with dynamic mechanical analyzer (DMA) with as little as $10 \%$ glycerol (wt.- $\%$ of GGM) as plasticizer.

Films can be strengthened by crosslinking agents that chemically modify polymers during preparation of filmforming solutions. Crosslinking agents are natural or synthetic molecules containing at least two reactive groups that are able to form inter- and/or intramolecular links between polymeric chains [14]. Glyoxal (ethanedial) is the smallest existing dialdehyde and is widely used in, among other things, permanent-press fabrics, dimensional stabilization of rayon and other fibers, leather tanning, and paper coat-ings [15]. Glyoxal forms hemiacetal bonds with hydroxyl groups, many of which are present in polysaccharides [16]. Crosslinking agents such as glyoxal or citric acid can improve the moisture resistance of hemicellulose-based films [17]. Crosslinking of starch with glyoxal results in increased rigidity and decreased moisture sorption of extruded foams [18]. The addition of glyoxal reduced the swelling ratio of hydroxypropyl cellulose films in water [19]. Glyoxal-crosslinking can also be used to increase the puncture strength of cotton seed protein-based films [20]. The aims of the present study were to crosslink GGM with glyoxal and to study the properties of crosslinked GGM-based films as a function of plasticizer dosage.

\section{Experimental}

2.1. Materials. Spruce galactoglucomannans (GGM) were obtained from process water of a Finnish pulp mill in an industrial-scale isolation trial after ethanol precipitation $[8$, $21]$. The carbohydrate composition of the precipitated material was characterized by $\mathrm{Xu}$ et al. and was found to consist of GGM at 80 mole- $\%$, with a small percentage of other carbohydrates (mainly xylose, galacturonic acid, and glucuronic acid) [8]. Along with carbohydrates, aromatic moieties from degraded lignin, lignans, and lipophilic substances, such as fatty acids, resin acids, steryl esters, and triglycerides are extracted from spruce wood in water and can be present in GGM at a minor content [22]. GGM was dissolved in water at $10 \mathrm{~g} / \mathrm{L}$, passed through a glass fiber filter to remove the small amount of nondispersible material, concentrated using a rotary evaporator, and lyophilized. Glyoxal was purchased from Sigma-Aldrich (Taufkirchen, Germany), sorbitol (Sorbidex S58/16603) from Cerestar (Krefeld, Germany), HPLC grade dimethyl sulfoxide (DMSO) from Lab-Scan (Dublin, Ireland), and $\mathrm{LiBr}$ and $\mathrm{NaNO}_{3}$ from Sigma-Aldrich. The $\mathrm{P}_{2} \mathrm{O}_{5}, \mathrm{MgCl}_{2}, \mathrm{Mg}\left(\mathrm{NO}_{3}\right)_{2}, \mathrm{KCl}$, and anhydrous $\mathrm{CaCl}_{2}$ with
TABLE 1: Film codes. The percentages are wt.- $\%$ of GGM.

\begin{tabular}{lc}
\hline Code & \multicolumn{1}{c}{ Description } \\
\hline GGM:5gox & $\begin{array}{c}\text { Film from GGM with 5\% } \\
\text { glyoxal }\end{array}$ \\
GGM:5gox/10sor & $\begin{array}{l}\text { Film from GGM with 5\% } \\
\text { glyoxal and 10\% sorbitol } \\
\text { Film from GGM with 5\% } \\
\text { glyoxal and 20\% sorbitol }\end{array}$ \\
GGM:5gox/20sor & $\begin{array}{l}\text { Film from GGM with 5\% } \\
\text { glyoxal and 30\% sorbitol }\end{array}$ \\
GGM:5gox/30sor & $\begin{array}{l}\text { Film from GGM with 5\% } \\
\text { glyoxal and 40\% sorbitol }\end{array}$ \\
GGM:5gox/40sor & Film from GGM with $40 \%$ \\
GGM/40sor & sorbitol \\
\hline
\end{tabular}

a granular size of $1-2 \mathrm{~mm}$ were from Merck (Whitehouse Station, NJ, USA).

2.2. Preparation of Films. Films were prepared from GGM with glyoxal at $5 \%$ (wt.- $\%$ of GGM) without plasticizer and with 10,20,30, and $40 \%$ sorbitol (wt.-\% of GGM). In addition, films were prepared without glyoxal, using $40 \%$ sorbitol. Film codes are shown in Table 1. GGM was dissolved in water under magnetic stirring at $85^{\circ} \mathrm{C}$ for $10 \mathrm{~min}$. The solution was cooled to $60^{\circ} \mathrm{C}$, glyoxal was added, and the solution was mixed by magnetic stirring for $4 \mathrm{~min}$ before the addition of sorbitol. The GGM content in the solutions was $10 \mathrm{~g} / \mathrm{L}$. When thicker films were prepared for dynamic mechanical analysis (DMA), the GGM content was $20 \mathrm{~g} / \mathrm{L}$. The solutions were degassed by ultrasonication under vacuum for $5 \mathrm{~min}$, cast into Teflon plates or Teflon-coated Petri dishes, and dried in a climate room at $50 \% \mathrm{RH}$ and $23^{\circ} \mathrm{C}$. The thickness of the films for DMA was approximately $100 \mu \mathrm{m}$; that of other films was approximately $40 \mu \mathrm{m}$. The films were conditioned at $50 \% \mathrm{RH}$ and $23^{\circ} \mathrm{C}$ before analyses, with the exception that samples for water sorption measurements were stored in vacuum desiccators over $\mathrm{P}_{2} \mathrm{O}_{5}$ at $0 \% \mathrm{RH}$.

2.3. Size Exclusion Chromatography. The lyophilized GGM powder and the films from GGM:5gox and GGM:5gox/20sor were mixed in water containing $0.1 \mathrm{M} \mathrm{NaNO}_{3}$ and in DMSO containing $0.01 \mathrm{M} \mathrm{LiBr}$ with magnetic stirring for three days, then filtered with $0.45 \mu \mathrm{m}$ syringe filters (GHP Acrodisc 13, Pall Corp., Ann Arbor, MI, USA). The samples were analyzed by high-performance size-exclusion chromatography (HPSEC) using a dn/ds value of 0.150 for the aqueous eluent and 0.064 for DMSO. The equipment as well as the method of HPSEC analysis was described by Pitkänen et al. [23].

2.4. Tensile Testing. The tensile strength, elongation at break, and Young's modulus of the films were determined at $23^{\circ} \mathrm{C}$ and $50 \% \mathrm{RH}$ (climate room) using an Instron 4465 universal testing machine with a load cell of $100 \mathrm{~N}$. The initial grip distance was $50 \mathrm{~mm}$ and the rate of grip separation $5 \mathrm{~mm} / \mathrm{min}$. Nine to 10 replicate specimens from each film type were measured. The specimens were $10 \mathrm{~mm}$ wide and 
approximately $80 \mathrm{~mm}$ long. The thickness of the specimens was measured with a micrometer (Lorentzen \& Wettre, Kista Sweden, precision $1 \mu \mathrm{m}$ ) at five points and an average was calculated.

2.5. Dynamic Mechanical Analysis. Dynamic mechanical analysis (DMA) of films was performed on a DMA 242 (Netzsch-Gerätebau GmbH, Selb, Germany), using a film tension clamp. Triplicate specimens of $5 \mathrm{~mm} \times 30 \mathrm{~mm}$ were prepared, and their thickness was determined as an average of two measurements with a Lorenzen \& Wettre micrometer at $1-\mu \mathrm{m}$ precision. The gap between the jaws at the beginning of the test was $9 \mathrm{~mm}$. A dynamic force of $0.2 \mathrm{~N}$ was applied at the frequency of $1 \mathrm{~Hz}$. The specimens were equilibrated at $-70^{\circ} \mathrm{C}$ for $5 \mathrm{~min}$, after which the storage modulus $\left(\mathrm{E}^{\prime}\right)$, loss modulus $\left(\mathrm{E}^{\prime \prime}\right)$, and tangent delta $(\tan \delta)$ were determined as a function of temperature from $-70^{\circ} \mathrm{C}$ to $100^{\circ} \mathrm{C}$ at a heating rate of $5^{\circ} \mathrm{C} / \mathrm{min}$. The glass transition temperature $\left(T_{g}\right)$ was taken as a peak temperature of $\mathrm{E}^{\prime \prime}$ at $1 \mathrm{~Hz}$ [24], which was determined by fitting a parabolic curve to $\mathrm{E}^{\prime \prime}$ data with Origin 7.5 (OriginLab Corporation, Northampton, MA, USA) software.

2.6. Water Sorption. A DVS Intrinsic sorption microbalance (Surface Measurement Systems, Alperton, Middlesex, UK) was used to collect water sorption isotherms. The experiments were carried out at $25^{\circ} \mathrm{C}$ and $\mathrm{RH}$ values from 0 to $90 \%$. The sample was hydrated stepwise in $10 \%$ RH steps by equilibrating the sample weight at each step. The moisture uptake was calculated according to:

$$
\text { Moisture uptake }=100 \frac{W_{\text {moist }}-W_{\text {dry }}}{W_{\text {dry }}},
$$

where $W_{\text {moist }}$ is the sample weight equilibrated at the chosen relative humidity and $W_{\text {dry }}$ is the weight of the dry sample.

2.7. Water Vapor Permeability. The water vapor permeability (WVP) was determined according to the ASTM E 96/E $96 \mathrm{M-}$ 05 standard [25]. In addition to the $\mathrm{RH}$ gradient recommended in the standard (0/54\%), the RH gradient of $33 / 86 \%$ was studied. Films were sealed on aluminum cups containing $43 \mathrm{~g} \mathrm{CaCl}_{2}$ as a desiccant or $25 \mathrm{~g}$ saturated $\mathrm{MgCl}_{2}$ solution to give an atmosphere of 33\% RH [26]. There was an air gap of $6 \mathrm{~mm}$ between the salt or salt solution and the underside of the film. The cups were placed in a desiccator cabinet equipped with a fan to circulate the air above the samples at a speed of $0.15 \mathrm{~m} / \mathrm{s}$. The cabinet was kept at $22^{\circ} \mathrm{C}$, and its $\mathrm{RH}$ was maintained at $54 \%$ using saturated $\mathrm{Mg}\left(\mathrm{NO}_{3}\right)_{2}$ solution when the desiccant was used inside the cups and at $86 \%$ using saturated $\mathrm{KCl}$ solution when the inner atmosphere was controlled with $\mathrm{MgCl}_{2}$.

The cups were weighed five to 10 times at intervals of $3 \mathrm{~h}-$ $3 \mathrm{~d}$. The temperature and $\mathrm{RH}$ of the cabinet were measured using a Rotronic HygroPalm RH meter (Bassersdorf, Switzerland) prior to each weighing. The water vapor transmission rate (WVTR) was calculated from the linear regression of the slope of weight gain versus time by dividing the slope by the test cell mouth area. The water vapor partial pressure at the underside of the film was calculated using the correction method described by Gennadios et al. [27]. The water vapor permeability (WVP) was obtained by multiplying the WVTR by the thickness of the film and dividing by the water vapor partial pressure difference between the two sides of the film. Three replicates of each film type were tested and their thickness was measured prior to testing at 10 points at $1 \mu \mathrm{m}$ precision.

2.8. Oxygen Permeability. The oxygen gas transmission rate (OTR) of the films was measured using an oxygen permeability (OP) tester with a coulometric sensor (Ox-Tran Twin; Modern Controls Inc., Minneapolis, MN, USA). The specimens were placed in the instrument for approximately $20 \mathrm{~h}$ prior to testing to condition them to the $\mathrm{RH}$ inside the test cells, which is reported in the instrument manual to be 50$75 \%$. The film was exposed to $100 \%$ oxygen on one side and to a mixture of $98 \%$ nitrogen and $2 \%$ hydrogen on the other side. The OP was calculated by multiplying the OTR by the thickness of the film and dividing it by the oxygen gas partial pressure difference between the two sides of the film. The measurements were carried out at $22^{\circ} \mathrm{C}$ and normal atmospheric pressure. The specimen area was $5 \mathrm{~cm}^{2}$, and the thickness of the film was measured after analysis at five points with a micrometer at $1 \mu \mathrm{m}$ precision. The OP was determined on four replicates of each film. However, in some cases, some of the replicates leaked and fewer than four successful measurements could be done.

\section{Results}

3.1. Film Formation. Pure GGM does not form a cohesive self-standing film without the addition of external plasticizer, such as glycerol or sorbitol. Moreover, a high dosage (30$40 \%$ ) of plasticizer is needed, which results in decreased tensile strength and increased moisture sensitivity of the films. When glyoxal was added as crosslinker at 5\% (wt.- \% of GGM), film preparation was successful at all sorbitol contents studied and even without the addition of sorbitol.

3.2. Molar Mass. The GGM powder and films from GGM:5gox and GGM:5gox/20sor were analyzed with HPSEC using both aqueous salt solution and organic DMSO as eluents. The weight average molar mass of all samples in the aqueous system was $32,000 \mathrm{~g} / \mathrm{mol}$. Thus, no increase in molar mass was observed with glyoxal addition. All samples, however, contained some aggregates seen as prepeak in light scattering signals (results not shown), which might somewhat increase the molar mass results. The recovery values based on the refractive index signal ranged from $72 \%$ to $89 \%$, so the samples were well soluble in the aqueous eluent used. The recovery was slightly lower for the crosslinked samples than for the GGM powder. In addition, the samples were analyzed in DMSO with $0.01 \mathrm{M} \mathrm{LiBr}$, which is an efficient solvent for hemicelluloses [23]. GGM powder dissolved rather well (recovery 75\%), and the film from GGM:5gox/20sor dissolved partly (recovery 54\%) in DMSO, but the unplasticized 
TABle 2: Peak temperature of loss modulus $\left(\mathrm{E}^{\prime \prime}\right)$ indicating $\alpha$ relaxation (glass transition, $T_{g}$ ) of films conditioned at $50 \% \mathrm{RH}$ (mean \pm standard deviations from three measurements). Sample coding as presented in Table 1.

\begin{tabular}{lc}
\hline Film & $T_{g} \pm$ sd $\left({ }^{\circ} \mathrm{C}\right)$ \\
\hline GGM:5gox & $83 \pm 2$ \\
GGM:5gox/10sor & $65 \pm 4$ \\
GGM:5gox/20sor & $53 \pm 5$ \\
GGM:5gox/30sor & $25 \pm 5$ \\
GGM:5gox/40sor & $5 \pm 6$ \\
GGM/40sor & $-4 \pm 2$ \\
\hline
\end{tabular}

GGM:5gox film was not soluble in DMSO. The molar masses of the GGM powder and the GGM:5gox/20sor film analyzed in DMSO were slightly lower and higher, respectively, compared to values obtained in the aqueous eluent.

3.3. Mechanical and Thermal Properties. The tensile strength of glyoxal-crosslinked films, being 22-24 MPa, was interestingly found to be independent on the plasticizer content, except with $10 \%$ sorbitol when the tensile strength was lower, $16 \mathrm{MPa}$ (Figure 1(a)). In comparison, the tensile strength of the noncrosslinked GGM/40sor film was $12 \mathrm{MPa}$. Thus the addition of $5 \%$ glyoxal doubled the tensile strength of films with $40 \%$ sorbitol. The elongation at break of crosslinked films slightly increased from 3.7\% to 7\%, and Young's modulus decreased from $740 \mathrm{MPa}$ to $490 \mathrm{MPa}$ as the amount of sorbitol increased from $10 \%$ to $40 \%$ (Figures $1(\mathrm{~b})$ and $1(\mathrm{c})$ ). The elongation at break of GGM/40sor films was similar to that of GGM:5gox/40sor films, but Young's modulus, and thus the stiffness of the reference GGM/40sor films, was clearly lower than that of any of the glyoxal-crosslinked films.

The storage modulus ( $\left.\mathrm{E}^{\prime}\right)$ of films at $50 \% \mathrm{RH}$ decreased (Figure 2) and loss modulus ( $\mathrm{E}^{\prime \prime}$ ) showed a peak (Table 2) with increasing temperature indicating $\alpha$-relaxation (glass transition, $T_{g}$ ). To eliminate the effect of variation in thickness of the films and the error in its measurement, the $\mathrm{E}^{\prime}$ in Figure 2 was normalized at $1 \mathrm{GPa}$, as explained by Mathew et al. [28]. The $\mathrm{E}^{\prime}$ decrease was steadily greater and the $T_{g}$ lower as the sorbitol content increased. Films with less than $30 \%$ sorbitol were in a glassy state at room temperature. The glass transition was detectable even in the films without sorbitol $\left(83^{\circ} \mathrm{C}\right)$, due to the plasticization with water. The moisture uptake of films at 50\% RH was 10-12\% (Figure 3). The effect of glyoxal crosslinking was also clearly seen, as the $T_{g}$ of the reference GGM/40sor film was $9^{\circ} \mathrm{C}$ lower than that of the GGM:5gox/40sor film.

3.4. Water Sorption. Crosslinking of GGM with glyoxal decreased the moisture uptake of films containing 40\% sorbitol at $40-90 \% \mathrm{RH}$ (Figure 3). At RHs from $10 \%$ to $50 \%$, the moisture uptake of films decreased with increasing sorbitol content. At higher RHs, from $70 \%$ to $90 \%$, the effect was the opposite, and the addition of sorbitol increased the moisture uptake of films.
3.5. Permeability Properties. The water vapor transmission rate (WVTR) and water vapor permeability (WVP) were determined at two different conditions, with an RH difference between the inner and outer sides of the film of about $50 \%$ in both cases. At RH gradient of $0 / 54 \%$, the lowest WVP values were determined for GGM:5gox/20sor, GGM:5gox/30sor, and GGM:5gox/40sor films (Table 3). The WVP of unplasticized films was clearly higher than that of the films containing sorbitol. The WVP of GGM:5gox/10sor and GGM/40sor films was slightly higher than that of the glyoxal-crosslinked films containing $20-40 \%$ sorbitol. At the gradient of $33 / 86 \%$, the WVTR and WVP increased steadily with increasing sorbitol content.

The oxygen transmission rate (OTR) measurement of GGM:5gox films was repeated several times, but the films leaked and no result was obtained. In contrast, two replicate OTR measurements of the sorbitol-plasticized GGM:5gox/10sor and GGM:5gox/20sor films and all OTR measurements of the other films were successful. Taking the standard deviations into account, there were no great differences in the oxygen permeability (OP) of films (Table 4). Only GGM:5gox/20sor film was distinguished with regard to the OP, which was lower than that of the other films.

\section{Discussion}

GGMs are a potential renewable and biodegradable filmforming material, but require a rather large amount of plasticizer to form cohesive films, and the mechanical performance of the highly plasticized GGM films is rather low. As indicated by tensile testing and DMA, addition of 5\% glyoxal clearly strengthened and stiffened the GGM films. The macromolecular mobility of the film components decreased with the addition of glyoxal, as shown by increased $T_{g}$ (Table 2). That is expected to be due to formation of hemiacetal bonds between glyoxal and GGM chains resulting in a network of crosslinked GGM, in addition to hydrogen bonding of GGM molecules. The formation of a crosslinked network is also supported by the fact that GGM and glyoxal, unlike pure GGM, formed cohesive films even without additional plasticizer. However, the HPSEC analysis in aqueous eluent did not show increase of the molar mass of GGM samples with glyoxal. This is most probably due to the reversible nature of formed hemiacetal bonds in aqueous solution. The insolubility of GGM:5gox film in DMSO, in which pure GGM dissolves well, is an indication of successful crosslinking. On the other hand, the partial solubility of GGM:5gox/20sor film in DMSO indicates that, in the sorbitol-plasticized films, the hemiacetal linkages might also be formed between glyoxal and hydroxyl groups of sorbitol instead of hydroxyl groups of GGM.

Interestingly, the effect of sorbitol dosage on the mechanical properties of the films was not straightforward. Classically, increasing amount of plasticizer is known to decrease the tensile strength and increase the elongation at break of films [29]. However, with previously studied guar gum and locust bean gum galactomannan films, increasing glycerol and sorbitol content from $20 \%$ to $40 \%$ (wt.- $\%$ of polymers) had a rather small effect on the tensile strength of films [30]. 


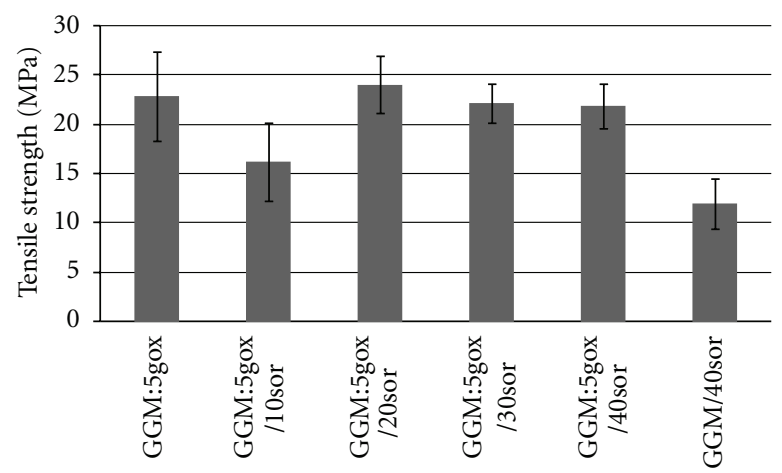

(a)

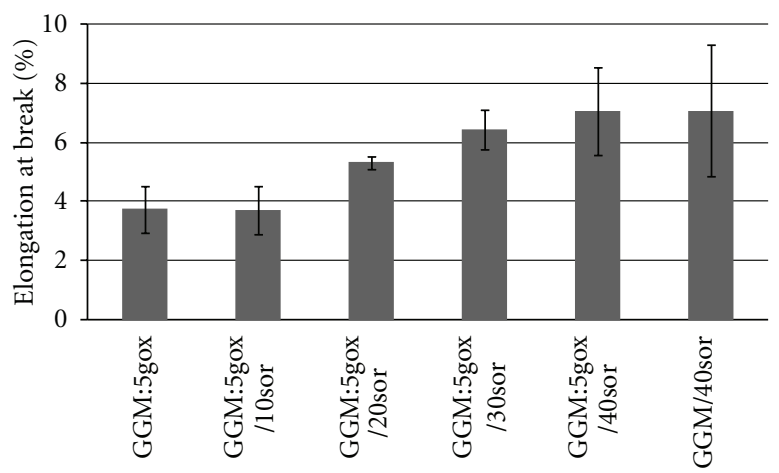

(b)

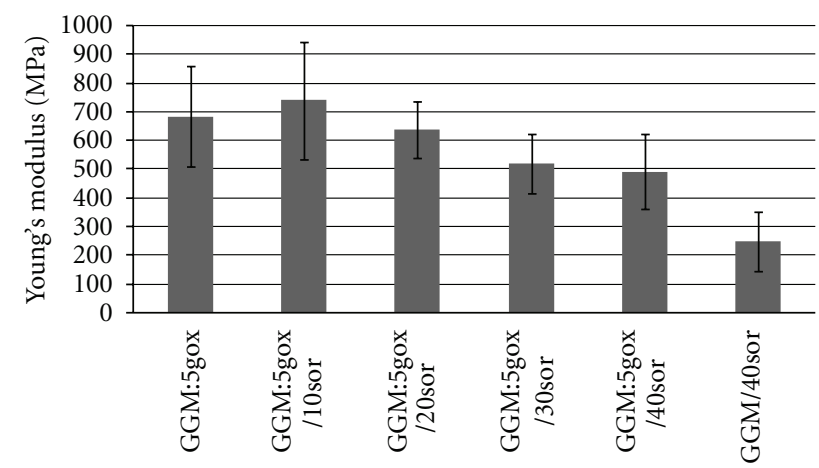

(c)

FIgure 1: (a) Tensile strength, (b) elongation at break, and (c) Young's modulus of films. The results are averages from 9 to 10 measurements, and the error bars indicate standard deviations. Sample coding as presented in Table 1.

TABLE 3: Water vapor transmission rate (WVTR) and water vapor permeability (WVP) of films (mean \pm standard deviations from three measurements). Sample coding as presented in Table 1.

\begin{tabular}{lcccc}
\hline \multirow{2}{*}{ Film } & \multicolumn{2}{c}{ WVTR $\pm \mathrm{SD}\left[\mathrm{g} /\left(\mathrm{m}^{2} \cdot \mathrm{d}\right)\right]$} & \multicolumn{2}{c}{$\mathrm{WVP} \pm \mathrm{SD}\left[\mathrm{g} \cdot \mathrm{mm} /\left(\mathrm{m}^{2} \cdot \mathrm{d} \cdot \mathrm{kPa}\right)\right]$} \\
& $(\mathrm{RH} \mathrm{0/54 \% )}$ & $(\mathrm{RH} \mathrm{32/86 \% )}$ & $(\mathrm{RH} 32 / 86 \%)$ \\
\hline GGM:5gox & $325 \pm 10$ & $748 \pm 38$ & $12.0 \pm 0.9$ & $23.5 \pm 0.4$ \\
GGM:5gox/10sor & $66 \pm 3$ & $850 \pm 29$ & $2.2 \pm 0.3$ & $26.9 \pm 4.4$ \\
GGM:5gox/20sor & $26 \pm 2$ & $900 \pm 68$ & $0.9 \pm 0.1$ & $29.1 \pm 1.1$ \\
GGM:5gox/30sor & $22 \pm 3$ & $939 \pm 37$ & $1.0 \pm 0.4$ & $27.4 \pm 0.8$ \\
GGM:5gox/40sor & $26 \pm 1$ & $1023 \pm 38$ & $1.1 \pm 0.2$ & $30.6 \pm 2.1$ \\
GGM/40sor & $49 \pm 6$ & $1068 \pm 41$ & $2.1 \pm 0.2$ & $33.2 \pm 6.1$ \\
\hline
\end{tabular}

TABLE 4: Oxygen transmission rate (OTR) and oxygen permeability (OP) of films (mean \pm standard deviations). Sample coding as presented in Table 1.

\begin{tabular}{lcr}
\hline Film & OTR $\pm \mathrm{sd}\left[\mathrm{cm}^{3} /\left(\mathrm{m}^{2} \cdot \mathrm{d}\right)\right]$ & $\mathrm{OP} \pm \mathrm{sd}\left[\mathrm{cm} 3 \cdot \mu \mathrm{m} /\left(\mathrm{m}^{2} \cdot \mathrm{d} \cdot \mathrm{kPa}\right)\right]$ \\
\hline GGM:5gox & nd & $\mathrm{nd}$ \\
GGM:5gox/10sor & $19 \pm 1$ & $10 \pm 3$ \\
GGM:5gox/20sor & $8 \pm 2$ & $3 \pm 0$ \\
GGM:5gox/30sor & $14 \pm 5$ & $8 \pm 4$ \\
GGM:5gox/40sor & $13 \pm 1$ & $8 \pm 1$ \\
GGM/40sor & $12 \pm 2$ & $7 \pm 2$ \\
\hline
\end{tabular}

Nd: not determined due to leaking of the film. 


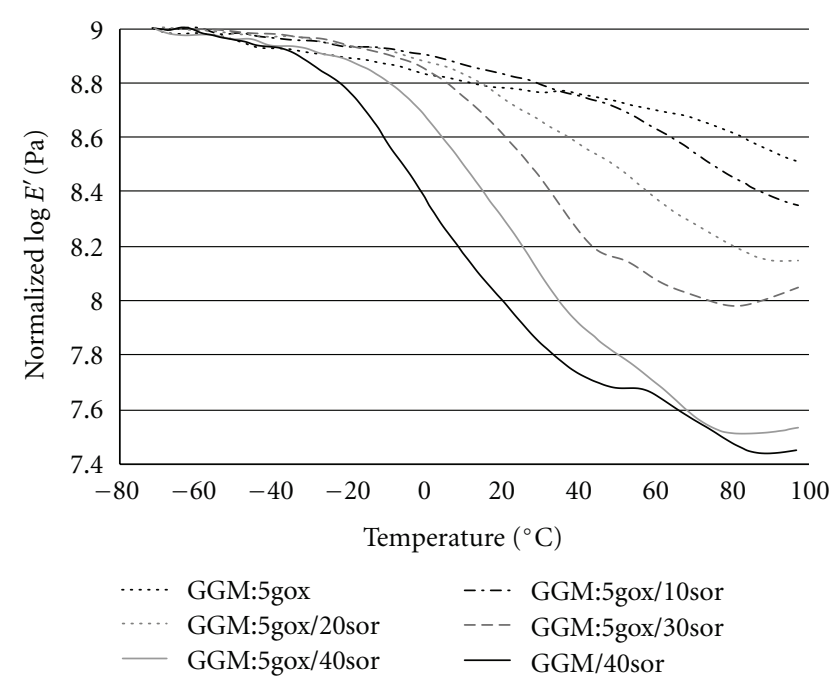

Figure 2: Logarithm of the storage modulus ( $\left.\mathrm{E}^{\prime}\right)$ spectra of films conditioned at $50 \% \mathrm{RH}$. The $\mathrm{E}^{\prime}$ at $-70^{\circ} \mathrm{C}$ was normalized at $1 \mathrm{GPa}$ for all the samples. Sample coding as presented in Table 1.

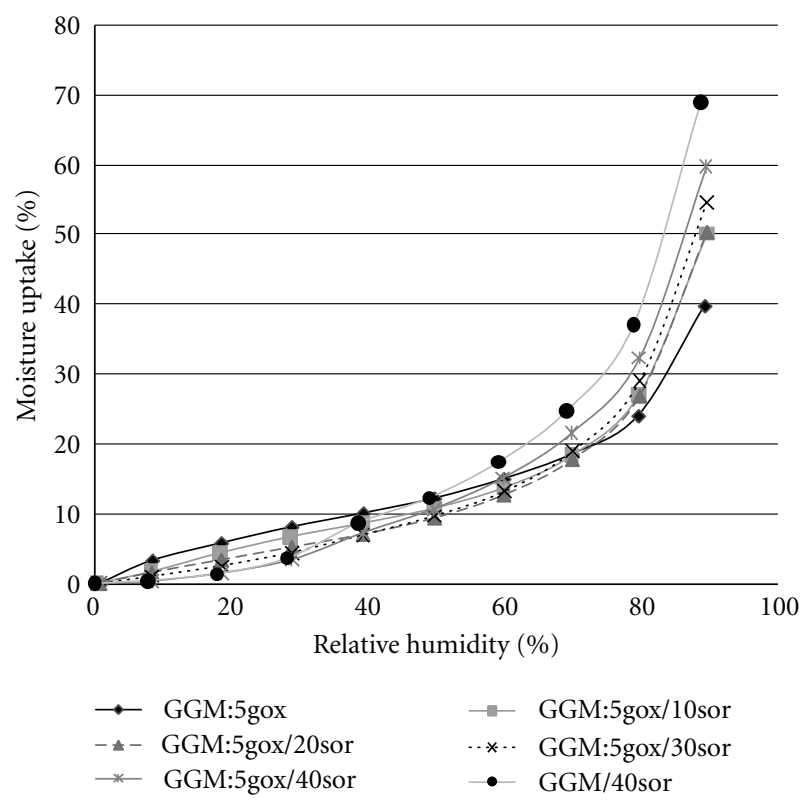

FIGURE 3: The water sorption isotherms of films. Sample coding as presented in Table 1.

The same phenomenon was observed with GGM films in the present study, as the tensile strength of glyoxal-crosslinked films was similar regardless of the sorbitol content, with the exception of the GGM:5gox/10sor film (Figure 1). During the preparation of the films, glyoxal was first allowed to interact with GGM for 4 min before the addition of sorbitol. Despite that, we cannot rule out the possibility of glyoxal forming hemiacetal bonds with the hydroxyl groups of sorbitol as well as with those of GGM, which would make some of the sorbitol less effective as plasticizer. However, the glyoxal dosage was constant at 5 wt.- $\%$ of GGM, whereas the content of sorbitol ranged from $10 \%$ to $40 \%$. Thus, in the highly plasticized films, there was not enough glyoxal to react with all the sorbitol. In contrast to tensile strength, the results of the elongation at break, Young's modulus, and especially DMA showed indeed clear plasticization of films with increasing sorbitol content (Figures 1 and 2). The elongation at break of all films was rather low, but there was a clear increasing trend with increasing amount of sorbitol. Young's modulus of films dropped approximately $200 \mathrm{MPa}$ when $40 \%$ sorbitol was present in the glyoxal-crosslinked films (films from GGM:5gox and GGM:5gox/40sor). In addition, DMA indicated that the films containing more sorbitol were less stiff and softened more at high temperature than the less plasticized films; that is, their $T_{g}$ was lower. The low tensile strength of the GGM:5gox/10sor film is an interesting result-one that is difficult to explain. Previously, the use of $10 \%$ glycerol, but not of sorbitol, in oat spelt arabinoxylan films was thought to induce an antiplasticization effect [31]. The effect of increasing glycerol content on $\beta$-transition of GGM films studied by dielectric analysis also suggested antiplasticization by glycerol [13]. However, the present data does not support the antiplasticization theory, according to which the tensile strength of a material increases with the addition of a small amount of plasticizer [32].

In our recent study, GGM films were prepared with a low content of plasticizer (glycerol) in the presence of $15 \%$ microfibrillated cellulose (MFC) [13]. Due to fracturing of the films during specimen preparation, the measurement of the tensile properties of films with less than $40 \%$ glycerol (wt.-\% of GGM), even in the presence of MFC, was not successful using the Instron tensile tester, which was successfully applied for all studied GGM-glyoxal films in the present work. Therefore, tensile testing of GGM-MFC composite films was performed using small specimens in a DMA. In contrast to the present study, a constant decrease in tensile strength of GGM-MFC films was detected with increasing plasticizer content [13]. The tensile strength of MFC-reinforced GGM films containing $10 \%$ glycerol as analyzed by DMA (34 MPa) was higher than that of any of the GGMglyoxal films in the present study. However, the glyoxalcrosslinked GGM films were easier to handle than the MFCreinforced films, also with low plasticizer content, and their tensile properties could thus be measured using the Instron device.

The effect of the amount of sorbitol on water sorption of glyoxal-crosslinked films depended on RH (Figure 3). At RHs below $50 \%$, the moisture uptake of films decreased with increasing sorbitol content, whereas at RHs above $70 \%$ the addition of sorbitol increased the water sorption. At RH $50 \%$, which was used in the tensile testing and DMA, the water content of films, and thus the plasticization by water, did not vary significantly. Previously, the addition of glycerol as plasticizer of GGM [13] and starch [33] was found to decrease the moisture uptake of films at low $\mathrm{RH}$ and increase it at high RH. The effect of sorbitol on glyoxal-crosslinked GGM films in the present study was similar. Thus, as considered for glycerol and starch by Godbillot et al. [33], at low RH sorbitol probably occupied the water sorption sites, whereas at high $\mathrm{RH}$, hydrophilic sorbitol dominated the global sorption behavior. 
The dependence of moisture uptake of films on $\mathrm{RH}$ most probably affected the obtained WVP results, which were studied using two different RH gradients of about $50 \%$ $(0 / 54 \%$ and $33 / 86 \%)$ (Table 3$)$. At lower RH $(0 / 54 \%)$, the glyoxal-crosslinked films with 20,30 , and $40 \%$ sorbitol had lower WVP than the films with $10 \%$ and without sorbitol. In contrast, at the higher RH (33/86\%), increasing sorbitol content increased the WVP. Thus, at higher RH, the highly plasticized films had higher water content and could have swelled more, leading to faster permeation of water molecules. The crosslinking seemed to slightly reduce the WVP of GGM films with $40 \%$ sorbitol at high RH. At lower RH, the WVP of the crosslinked films was half of that of GGM/40sor films. Interestingly, the unplasticized GGM:5gox film had the highest WVP of the films studied at the lower RH $(0 / 54 \%)$, $12.0 \mathrm{~g} \cdot \mathrm{mm} /\left(\mathrm{m}^{2} \cdot \mathrm{d} \cdot \mathrm{kPa}\right)$, but even though its WVP increased with increasing RH to $23.5 \mathrm{~g} \cdot \mathrm{mm} /\left(\mathrm{m}^{2} \cdot \mathrm{d} \cdot \mathrm{kPa}\right)$; it was lower than that of the other films at high RH $(33 / 86 \%)$. The OP measurements of that film, which were done at RH 50-75\%, were not successful probably due to pinholes in the film, leading to leaking of oxygen. This indicates that the structure of the unplasticized film at about $50 \% \mathrm{RH}$ was not compact. At RH 33/86\%, swelling took place, which had the potential to block the pinholes. Thus, at high $\mathrm{RH}$, increased water content and the swelling of the film, which was lower when sorbitol was not present, played the biggest role in affecting WVP. The OP results of the films (at RH 50-75\%) are in agreement with the WVP data at the lower RH (0/54\%), as the presence of sorbitol improved the oxygen barrier properties of the films (Table 4). The GGM:5gox/20sor film had the lowest OP, $3 \mathrm{~cm}^{3} \cdot \mu \mathrm{m} /\left(\mathrm{m}^{2} \cdot \mathrm{d} \cdot \mathrm{kPa}\right)$, indicating that this plasticizer content was optimal, on one hand preventing the formation of pinholes and on the other hand not exceedingly increasing the swelling.

The WVTR data can be compared with the WVP, calculation of which takes into account the original thickness of the films (Table 3). Due to variations in thickness of some of the replicate specimens, the standard deviations of the WVP results at $\mathrm{RH} 33 / 86 \%$ also vary. In contrast, the standard deviations of the WVTR values are rather similar. This indicates that the differences in thickness did not affect the amount of water vapor passed through the films. Thus, it can be speculated that the WVP of the films was mostly governed by the solubility of water in the films, not by diffusivity, though both can affect the permeability properties of films. Corresponding argumentation cannot be done about the mechanisms of oxygen permeation based on the present OTR and OP data (Table 4), because the standard deviations varied similarly in both the OTR and OP results.

Potential applications for GGM-based films could be in the packaging industry, for example, as biodegradable food packages. Thus, mechanical strength, flexibility, and moisture and gas barrier properties are required to protect the packaged product from mechanical stress and migration of moisture and other volatiles to and from the outside environment. The tensile strength of glyoxal-crosslinked GGM films was comparable to that of many other bio-based or synthetic materials currently used in packaging [34]. However, the elongation at break of GGM films was rather low compared to that of materials in commercial use [34]. The WVP of GGM films at the gradient of $0 / 54 \%$ was similar or lower than that of other polysaccharide- or protein-based films, but higher than that of polyethylene films [35] and further increased with increasing $\mathrm{RH}$. We have previously discussed our results on the OP of GGM films in comparison with those of films from other mannans and starch and a commercial film containing ethylene vinyl alcohol with layers of polyethylene on both sides [10]. Those, as well as our present results, support the statement that GGM-based films hold potential as oxygen barrier materials, although only in the presence of a plasticizer. Despite crosslinking of GGM with glyoxal, the studied films are still expected to be biodegradable. As discussed earlier, the formed hemiacetal bonds are reversible, that is, most likely break in water or moist environment, after which the components are conventionally degraded further by naturally occurring microorganisms.

\section{Conclusion}

Crosslinking GGM with 5\% glyoxal resulted in a strengthened polymer network and films with higher tensile strength, Young's modulus, storage modulus ( $\left.\mathrm{E}^{\prime}\right)$, and glass transition temperature $\left(T_{g}\right)$ than uncrosslinked sorbitol-plasticized films. The glyoxal-crosslinked films could be prepared and studied with different amounts of sorbitol as plasticizer and even without the use of polyol plasticizer, which is not successful from pure GGM. The effect of increasing sorbitol content was seen as increased elongation at break and moisture content at high RH and decreased Young's modulus and $T_{g}$ of films, but interestingly the tensile strength did not decrease along the addition of sorbitol. At low $\mathrm{RH}$, the addition of sorbitol improved the water vapor barrier properties of the films, but, at high RH, the WVP increased with increasing sorbitol content. Presence of sorbitol in GGMs films was necessary to obtain oxygen barrier materials. Spruce GGMs are promising renewable polymers and a potential byproduct from the forestry industry. In the present study, they were shown for the first time to produce self-standing films in the presence of a suitable crosslinking agent. The properties of GGM-based biodegradable films for various future applications can be further tailored by optimizing the type and content of crosslinking and plasticization agents.

\section{Acknowledgments}

Forestcluster Ltd's Future Biorefinery programme and the Finnish Funding Agency for Technology and Innovation (Tekes) are gratefully acknowledged for their financial support, along with Leena Pitkänen (University of Helsinki) for the HPSEC analysis.

\section{References}

[1] G. Swift, "Directions for environmentally biodegradable polymer research," Accounts of Chemical Research, vol. 26, no. 3, pp. 105-110, 1993.

[2] I. Moura, A. V. Machado, F. M. Duarte, and R. Nogueira, "Biodegradability assessment of aliphatic polyesters-based 
blends using standard methods," Journal of Applied Polymer Science, vol. 119, no. 6, pp. 3338-3346, 2011.

[3] S. Willför, K. Sundberg, M. Tenkanen, and B. Holmbom, "Spruce-derived mannans-a potential raw material for hydrocolloids and novel advanced natural materials," Carbohydrate Polymers, vol. 72, no. 2, pp. 197-210, 2008.

[4] T. Persson, A. K. Nordin, G. Zacchi, and A. S. Jönsson, "Economic evaluation of isolation of hemicelluloses from process streams from thermomechanical pulping of spruce," Applied Biochemistry and Biotechnology, vol. 137-140, no. 1-12, pp. 741-752, 2007.

[5] A. C. Albertsson, J. Voepel, U. Edlund, O. Dahlman, and M. Söderqvist-Lindblad, "Design of renewable hydrogel release systems from fiberboard mill wastewater," Biomacromolecules, vol. 11, no. 5, pp. 1406-1411, 2010.

[6] T. Song, A. Pranovich, and B. Holmbom, "Characterisation of Norway spruce hemicelluloses extracted by pressurised hotwater extraction (ASE) in the presence of sodium bicarbonate," Holzforschung, vol. 65, no. 1, pp. 35-42, 2011.

[7] E. Sjöström, Wood Chemistry Fundamentals and Applications, Academic Press, San Diego, Calif, USA, 1993.

[8] C. Xu, S. Willför, K. Sundberg, C. Petterson, and B. Holmbom, "Physico-chemical characterization of spruce galactoglucomannan solutions: stability, surface activity and rheology," Cellulose Chemistry and Technology, vol. 41, no. 1, pp. 51-62, 2008.

[9] J. Hartman, A. C. Albertsson, M. S. Lindblad, and J. Sjöberg, "Oxygen barrier materials from renewable sources: material properties of softwood hemicellulose-based films," Journal of Applied Polymer Science, vol. 100, no. 4, pp. 2985-2991, 2006.

[10] K. S. Mikkonen, M. I. Heikkilä, H. Helén, L. Hyvönen, and M. Tenkanen, "Spruce galactoglucomannan films show promising barrier properties," Carbohydrate Polymers, vol. 79, no. 4, pp. 1107-1112, 2010.

[11] U. Edlund, Y. Z. Ryberg, and A. C. Albertsson, "Barrier films from renewable forestry waste," Biomacromolecules, vol. 11, no. 9, pp. 2532-2538, 2010.

[12] K. S. Mikkonen, A. P. Mathew, K. Pirkkalainen et al., "Glucomannan composite films with cellulose nanowhiskers," Cellulose, vol. 17, no. 1, pp. 69-81, 2010.

[13] K. S. Mikkonen, J. S. Stevanic, C. Joly et al., "Composite films from spruce galactoglucomannans with microfibrillated spruce wood cellulose," Cellulose, vol. 18, no. 3, pp. 713-726, 2011.

[14] C. Marquié and S. Guilbert, "Formation and properties of cottonseed protein films and coatings," in Protein-Based Films and Coatings, A. Gennadios, Ed., CRC Press, New York, NY, USA, 2002.

[15] R. J. Lewis, Hawley's Condensed Chemical Dictionary, John Wiley \& Sons, Hoboken, NJ, USA, 15th edition, 2007.

[16] N. R. Eldred and J. C. Spicer, "Glyoxal: a unique wet-strength agent," Tappi, vol. 46, no. 10, pp. 608-612, 1963.

[17] M. Gröndahl, L. Eriksson, P. Gatenholm, and T. Hjertberg, "Polymeric film or coating comprising hemicellulose," Patent WO2008103123, August 2008.

[18] Y. U. Nabar, D. Draybuck, and R. Narayan, "Physicomechanical and hydrophobic properties of starch foams extruded with different biodegradable polymers," Journal of Applied Polymer Science, vol. 102, no. 1, pp. 58-68, 2006.

[19] S. Suto and K. Suzuki, "Crosslinked hydroxypropyl cellulose films retaining cholesteric liquid crystalline order: 2. Anisotropic swelling behaviour in water," Polymer, vol. 38, no. 2, pp. 391-396, 1997.
[20] C. Marquié, A. M. Tessier, C. Aymard, and S. Guilbert, "How to monitor the protein cross-linking by formaldehyde, glutaraldehyde or glyoxal in cotton-seed protein-based films?" Nahrung, vol. 42, no. 3-4, pp. 264-265, 1998.

[21] S. Willför, P. Rehn, A. Sundberg, K. Sundbgerg, and B. Holmbom, "Recovery of water-soluble acetylgalactogluco-mannans from mechanical pulp of spruce," Tappi Journal, vol. 2, no. 11, pp. 27-32, 2003.

[22] F. Örså, B. Holmbom, and J. Thornton, "Dissolution and dispersion of spruce wood components into hot water," Wood Science and Technology, vol. 31, no. 4, pp. 279-290, 1997.

[23] L. Pitkänen, L. Virkki, M. Tenkanen, and P. Tuomainen, "Comprehensive multidetector HPSEC study on solution properties of cereal arabinoxylans in aqueous and DMSO solutions," Biomacromolecules, vol. 10, no. 7, pp. 1962-1969, 2009.

[24] M. T. Kalichevsky and J. M. V. Blanshard, "The effect of fructose and water on the glass transition of amylopectin," Carbohydrate Polymers, vol. 20, no. 2, pp. 107-113, 1993.

[25] ASTM, Standard Test Methods for Water Vapor Transmittance of Materials, Designation E 96/E 96M-05, 2005.

[26] T. P. Labuza, A. Kaanane, and J. Y. Chen, "Effect of temperature on the moisture sorption isotherms and water activity shift of two dehydrated foods," Journal of Food Science, vol. 50, no. 2, pp. 385-391, 1985.

[27] A. Gennadios, C. L. Weller, and C. H. Gooding, "Measurement errors in water vapor permeability of highly permeable, hydrophilic edible films," Journal of Food Engineering, vol. 21, no. 4, pp. 395-409, 1994.

[28] A. P. Mathew, W. Thielemans, and A. Dufresne, "Mechanical properties of nanocomposites from sorbitol plasticized starch and tunicin whiskers," Journal of Applied Polymer Science, vol. 109, no. 6, pp. 4065-4074, 2008.

[29] G. S. Banker, "Film coating theory and practice," Journal of Pharmaceutical Sciences, vol. 55, no. 1, pp. 81-89, 1966.

[30] K. S. Mikkonen, H. Rita, H. Helén, R. A. Talja, L. Hyvönen, and M. Tenkanen, "Effect of polysaccharide structure on mechanical and thermal properties of galactomannan-based films," Biomacromolecules, vol. 8, no. 10, pp. 3198-3205, 2007.

[31] K. S. Mikkonen, S. Heikkinen, A. Soovre et al., "Films from oat spelt arabinoxylan plasticized with glycerol and sorbitol," Journal of Applied Polymer Science, vol. 114, no. 1, pp. 457-466, 2009.

[32] D. Lourdin, H. Bizot, and P. Colonna, “'Antiplasticization' in starch-glycerol films?” Journal of Applied Polymer Science, vol. 63, no. 8, pp. 1047-1053, 1997.

[33] L. Godbillot, P. Dole, C. Joly, B. Rogé, and M. Mathlouthi, "Analysis of water binding in starch plasticized films," Food Chemistry, vol. 96, no. 3, pp. 380-386, 2006.

[34] G. Robertson, "State-of-the-art biobased food packaging materials," in Environmentally Compatible Food Packaging, E. Chiellini, Ed., Woodhead Publishing Limited, Cambridge, UK, 2008.

[35] Y. Zhang and Z. Liu, "Starch-based edible films," in Environmentally Compatible Food Packaging, E. Chiellini, Ed., Woodhead Publishing Limited, Cambridge, UK, 2008. 

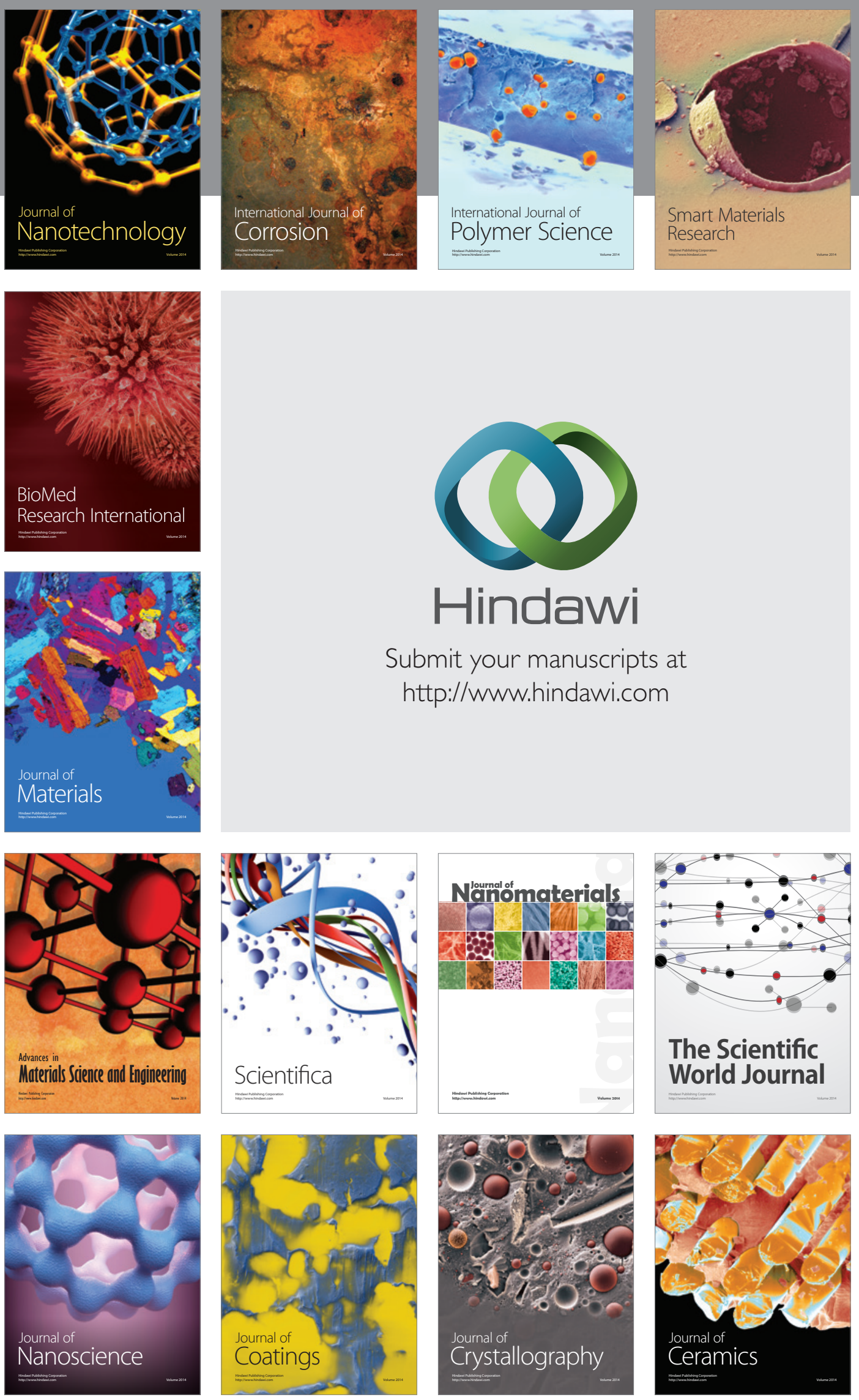

The Scientific World Journal

Submit your manuscripts at

http://www.hindawi.com

\section{World Journal}

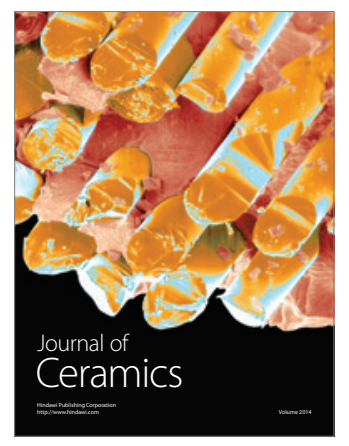

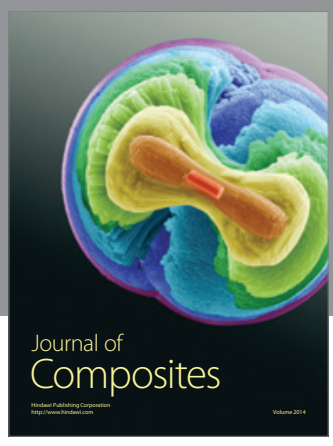
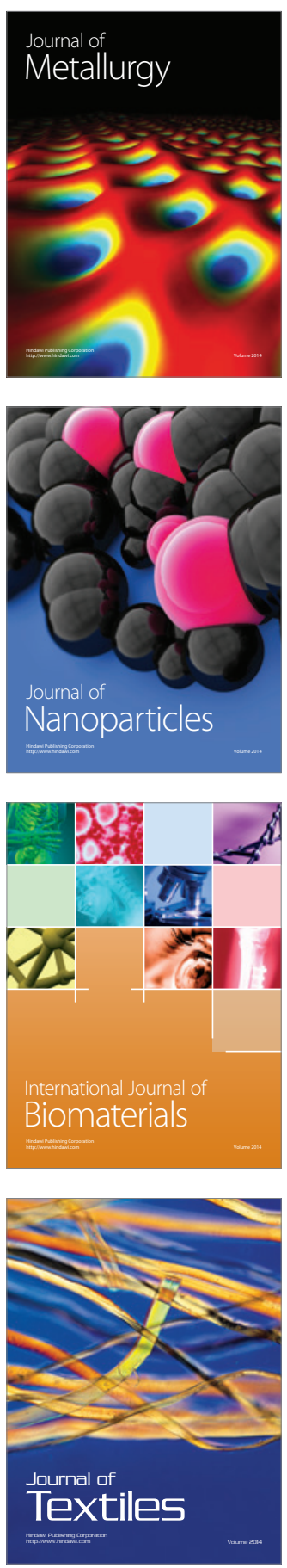